\title{
IsiZulu and English in KwaZulu-Natal rural schools: how teachers fear failure and opt for English
}

\begin{abstract}
In this article, factors inhibiting the use of mother tongue as the language of learning and teaching (LoLT) in rural foundation phase classes is investigated. I analysed qualitative data from focus group interviews with 20 foundation phase teachers that were selected through purposive sampling. Findings show that factors such as prior learner knowledge, better opportunities for children, time constraints, low self-concepts of African teachers, failure of the education system, teachers' lack of proficiency in the language of teaching and learning, directly translated resources, lack of parental involvement in decision making, and 'invisible' school language policies inhibit the use of children's primary language in the classroom. These nine factors are discussed and the article makes recommendations to suggest ways to alleviate these challenges.
\end{abstract}

Keywords: mother tongue teaching, foundation phase, rural schools, language in education policy, teachers' self concept

Nontokozo Mashiya, School of Education Studies; University of KwaZulu-Natal. E-mail: Mashiya@ukzn.ac.za.

South African Journal of Childhood Education | 2011 1(1): 19-31 | ISSN: 2223-7674 | ৫ UJ 


\section{Introduction and background}

This study arises from the challenges foundation phase student teachers encounter when they enter teaching practice. The report shows that pre-service teachers who learn about practice in schools are concerned about the language of pedagogy. These students are the custodians of the new programme offered for the post graduate certificate in education (PGCE) by one South African university. This programme is unique in that it is offered in the medium of instruction of schools, isizulu, which is rare in higher education institutions. The programme was introduced to actively support the transformation of the country. The introduction of the bilingual foundation phase programme taught in English and isiZulu emanates from two direct sources. These are the Language in Education Policy of 1997; and the language policy in one South African university, where the students are registered. The Language in Education Policy of 1997 stipulates that foundation phase learners are addressed in mother tongue, while the first additional language used in Grade 4 as the medium of instruction is introduced. Therefore, the need arose to train teachers to be able to teach in the primary language of the children in the schools where they are likely to teach in future. The university language policy, which was revised to accommodate African languages in a higher education institution, facilitated this programme. Two foundation phase specialisation modules, Literacy and Life Skills were designed accordingly and are offered in a dual medium of instruction, isiZulu and English. Students specialising in isiZulu are placed in isizulu medium schools during the teaching practical, while the remainder goes to English medium schools. These students encounter difficulty in schools when they have to practice the skills they have learnt at the university. Schools do not afford them the opportunity to teach in isizulu, even though they are isiZulu medium schools. Students discovered that teachers use a combination of a mother tongue and English in their teaching in the first grades ( $R$ and 1$)$; and in Grade 2 and 3 they use largely English. The additive bilingual approach emphasised by the Language in Education Policy is not being implemented.

Given the above, it therefore became apparent that some foundation phase (FP) teachers in rural and township schools do not implement the Language in Education Policy (LiEP) of 1997 as expected. It therefore became imperative to conduct a study to find out why teachers do not implement the policy. The LiEP stipulates that foundation phase learners should be taught in their mother tongue. Government Gazette nr. 30880 of 2008 contains the policy and states that a first additional language (FAL) should be introduced six months into Grade 1 as a subject of language use, but not as medium of teaching. The language children know best when they first enter school is recommended as the language of learning and teaching (Alexander, 2009). This language is the most individual and direct means through which individuals think, formulate ideas and give meaning to emotions (Alexander, 2002). The South African Schools Act 84 of 1996 states that a school governing body (SGB) may determine the language policy of the school. Parents have the right to choose the language medium through which they want their children to be taught. It is also stated in the LiEP that 
parents exercise the minors' (learners') rights in choosing the language of learning and teaching (Department of Education, 1997). The school governing body plays a role in deciding the language to be used as language of learning and teaching (LoLT). There is thus an inherent tension between different policies. Hypothetically, parents in rural KwaZulu-Natal (KZN) may vote to have English as medium of instruction in their schools. This article identifies this tension as one of the possible reasons why teachers act the way they do.

University students mentioned that teachers complain about the way the students teach, since they use African languages. Teachers say that their learners would not understand as a result they will have to start afresh and re-teach those sections when the teaching practice period is over. From the view of the teachers that would be a waste of time. This shows another tension in classroom practice. I developed an interest in conducting an investigation to explore why teachers are acting contrary to the LiEP of 1997. During the systemic evaluation conducted by the Department of Education (DoE) in 2001 and again in 2007, the survey showed poor and low levels of reading ability. The Monitoring Learning Achievement (MLA) was one of the first, large, cross national studies of quality in which South Africa participated. In addition, the Progress in the International Reading Strategy Study (PIRLS) revealed that in 2007, South Africa was the weakest of 45 countries (Dada, Dipholo, Hoadley, Khembo, Muller \& Volmink, 2009). No doubt this may be caused partly by the lack of focus in terms of the languages used to teach young learners, whose literacy is still emerging.

\section{Why teach in mother tongue?}

The language children know best when they first enter school (Alexander 2009) is recommended as the language of learning and teaching. For a child to communicate and become fully functional being, the primary language of children should be well developed. This not only occurs in a home context but should continue to the end of the foundation phase level. Alexander (2002) asserts that in early childhood, effective teaching begins with and builds on what children already know and can do. This supports the ideas of the LiEP and its additive bilingual teaching approach. Hay (2009) supports the principle of the use of learners' first language for as long as possible because this is associated with high academic achievement.

Stories are a way of teaching literacy in the foundation phase, where learners are trained to listen and speak, as one of the literacy learning outcomes. This is well done in a language a child knows. Alexander (2002) supports the idea that telling and listening to stories are highly valued because through stories, children are exposed to rich and complex forms of language. This privilege is tarnished when teaching is done in another language. As such, this practice will eliminate the number of children who are labelled 'remedial'. Ebrahim (2009) states that non-English mother tongue speakers in English medium schools are taught and assessed in an English mother tongue curriculum. If they do not do well, they are perceived as 'remedial'. Skutnabb-Kangas (2009) argues that learning through a foreign, second or third language curtails the 
development of children's capabilities, perpetuates poverty and can and does cause serious mental harm.

Rose \& Meyer (2000) argue that a curriculum, flexible and supportive of all learners should be developed. A curriculum to benefit and scaffold the child is one delivered through the language the child understands. That is, a curriculum designed approach to increase flexibility in teaching; and decrease the barriers that frequently limit student access to materials and learning in classrooms (Rose \& Meyer, 2002).

\section{General factors inhibiting mother tongue teaching}

Studies indicate that teachers in some schools do not teach in African languages because of their perceptions around mother tongue teaching. Parents see English as the language of power (Kunene, 2009). Research shows that when faced with having to choose between English and an African language as the LoLT, most parents and learners opt for English, the language they believe would empower them the most. African languages are viewed as languages of communication and not of learning. Most schools are struggling to implement the policy, thus confirming the gap between policy and practice and the inherent social tensions associated with the policy.

Debates around using mother tongue as a medium of instruction argue that people should not bother maintaining and developing their languages, when, in any case, everything happens in English (Alexander, 2002). Alexander addressed the main issue, that is, how we can move from the existing situation, where the languages of the former colonial powers dominate, to where the indigenous African languages become dominant (Alexander, 2003) because some teachers do not see the importance or benefits attached to mother tongue teaching in the early years. It appears in literature that teaching in the medium of instruction of an African language is not an easy practice, yet it has cognitive benefits for learners. Mashiya (2010) highlights these challenges by reflecting on her experiences of using mother tongue as the LoLT. She argues that resources for academic learning and teaching are a major problem. It was shown that teaching in mother tongue consumes more time than teaching in English. This is because materials are first translated into isizulu; and students produce large amounts of work compared to what is produced by students, who are learning in English. When taught in mother tongue, students are expected to perform above the norm because the literature outlines that teaching through an additional language constitutes a barrier to effective teaching and learning (lyamu \& Ogiegbaen, 2007), despite the challenges encountered in the process.

Some studies indicate that the language is the instrument that retards the implementation of the curriculum. In a case where African languages have to be used, there is a shortage of resources and terminology as Mashiya (2010) reflected on, in her experiences of mother tongue teaching in higher education.

To investigate the tensions in classroom practice I conducted the study that addressed the following research questions: 
- What motivates foundation phase teachers in some rural schools in KZN to teach contrary to the Language in Education Policy of 1997?

- How do parents contribute to the way teachers teach?

- How does the school language policy support what the teachers do in their classrooms?

\section{Theoretical framework: escaping from and avoiding negativity}

In reflecting on the research questions I decided to use the escape avoidance theory (Baumeister, 1990) as conceptual tool for understanding human motivation. This theory clarifies the motivational drivers which make people choose the way they do things. It helps to understand, explain and handle many human behaviour situations at different levels of need (Maslow, 1955). According to Baumeister (1990) and Heatherton \& Baumeister (1991), as cited by Tassava and Ruderman (1999), certain behaviours are motivated by the desire to escape negative effects. I used this theory as lens by thinking about the teachers: they associate low proficiency in English with mother tongue teaching, therefore avoiding teaching learners in their mother tongue because of this 'negative' effect. They hope that learners will gain proficiency in a language associated with power, so they introduce learners to English before the approved grade. Their reasoning has a certain logic to it, due to their own life experience and the social power of language that they encountered first hand.

The escape avoidance theory is furthermore also useful because it highlights how people avoid situations they do not wish to confront. It is thus a way of avoiding negativity. Hopkins (2005) adds that while behaviour is almost always motivated, it is usually biologically, culturally and situationally determined. Viewed from this perspective, teachers wish to prepare the children for a 'positive' future. The reaction of escaping a situation can also apply to any uncomfortable situation or encounter. Teachers regard mother tongue instruction as an 'aggressive' situation which they feel is uncomfortable. Their conflict is based on their view of what will benefit the children they teach and perhaps also what they see as the parents' view. The escape-avoidance theory is just a nonviolent form of retaliatory aggression in that it is also a means of defending oneself against future attacks (Baron \& Richardson, 1994).

This theory was used to develop semi-structured interview questions as the instrument to generate data in this inquiry. Questions that were asked were around what motivates teachers to shy away from what is regarded as a strong pedagogic principle in foundation phase education. Therefore questions were formulated through the lens of escape avoidance theory. 


\section{Research methodology}

\section{Sampling and data collection}

The study was conducted as a generic qualitative inquiry, using focus group data. The sampling strategy was purposive. I selected twenty foundation phase teachers, who teach in rural schools in Grade R-2. Only these grades were selected because if Grade 3 had been selected, teachers would have given the excuse that they were preparing the children for Grade 4, where English is supposed to be the medium of instruction. Following a complaint by the university students after a teaching practicum, it became obvious that foundation phase teachers teach in English in the Grade R classes. Only schools revealed by students as schools teaching in English were sampled for this investigation. Only rural schools were purposively sampled because most rural schools in this province have learners who are not diverse in terms of the language. Therefore they have a language policy that promotes the use of an African language as the LoLT. In KwaZulu-Natal, most of the learners in the rural schools use isizulu as primary language, a language that is widely spoken in the province. Teachers in these schools employ a combination of rural teachers and teachers from urban areas. As a result of their original contexts, their degree of fluency in African languages, and specifically isizulu, is not the same.

\section{Instrument}

I decided to use focus group interviews and classroom observations. Focus group interviews were used as data gathering instrument because this method allows the respondents to speak without limit in a simulation of a conversation, with the advantages of turn-taking and leading (Henning, 2004). It also allows the interviewer to do follow up on the answers given by the respondents; this is referred to by Henning (2004) as a two way communication. It also allows the interviewer to deviate if need be. This instrument is believed to be the best in exploring the factors that motivate teachers to ignore the contents of the language policy. The focus groups were conducted at three schools, where contextual observation yielded some background data as well.

\section{Data analysis}

Data were transcribed and analysed according to Giorgi (1975) 'phenomenological steps' of analysis of word data. In the first step, transcripts were read to get a general idea of the factors that motivate the teachers to teach in English. Secondly, transcripts were read to identify the conversational transactions; each transaction signified a unit of meaning. Thirdly, the redundancies in the units of meaning were eliminated. Fourthly, respondent language was transformed into the language of science; and lastly, the insights were synthesised into a description of what motivates teachers to teach contrary to the LiEP of 1997. The data were thus transformed or converted from 
'raw' data to social science data. From these data the most emphasised points in the discussion were identified as themes of the findings.

\section{Findings: steering clear of failure}

Nine themes were identified in the data of the study. The themes that highlight the use of English and the general language practice in the teachers' classroom are: children's competence in two languages and their prior knowledge; the belief that English advances the children; there is too little time to work only in isiZulu and then to introduce English; African teachers' say their own self concepts and sense of inadequacy are a factor for their choice; the perception of the failure of the education system; teachers' lack of proficiency in isizulu; directly translated resources; lack of parental involvement, and an 'invisible' school language policy.

\section{Children's dual language competence and their prior knowledge}

Teachers point to the young learners to justify their actions, which deviate from what is expected of them. One teacher stated:

When these children enter school, they enter with a mixture of English and isizulu. When we teach we use both languages for learners to understand. When we teach we start from where children are, for example they come to school with knowledge of numbers days of the week, months of the year and even some rhyme in English.

Findings highlight that a challenge is posed by the learners themselves. They lack mother tongue vocabulary. They are motivated by parents who do not speak African languages correctly. Some parents are educated and they equate this with knowledge of English and therefore they expose their children to English early. As a result the children of such parents fail to benefit when the teacher uses a correct African language. For the benefit of children, teachers use code switching, which is dominated by English.

The above response is typically what motivates teachers to teach in English because learners come with some knowledge of it and with no knowledge of counting or months of the year in their own vernacular. One lesson observed proved that even mathematical problems given to learners were in English. This is what a Grade 1 teacher wrote on the board for learners:

Sipho has six sweets. He has two friends. How many sweets is each of them going to get?

This would have been said in mother tongue in a clear and easy way but the teacher preferred to write it in English for learners who do not even have well developed reading skills at this age. Learners would have difficulty trying to understand the language, while trying to work out the sum.

\section{The belief that English advances the children}

Teachers advocate for the teaching of English because they experience learners with matriculation certificates who lack proficiency in English. One respondent said, 
We have children in the area who passed Grade 12, but they are not proficient in English. They cannot answer even a simple question. Then we do not want to contribute and produce more learners who are unable to speak.

Teachers say that African children who went to isiZulu medium schools have a problem communicating in English. Their speaking skills are seriously underdeveloped. This prevents children from getting decent jobs and from travelling and working abroad.

\section{African teachers' say their own self concepts and sense of inadequacy are a factor for their choice}

Some teachers believe that teaching in isiZulu is time consuming. They mention that a short English word turns into a long word. One teacher gave the following example:

When you give them an activity to write numbers for example of a number 'nine' which consist of four letters but when translated into isizulu it turns into a very long word 'isishiyagalolunye'. When a Grade 1 child writes this number it turns into a sentence which fills the whole page.

Teachers make the point that when this word has to be written by an emergent writer it fills the whole page because they cannot control their handwriting in Grade 1. This takes a lot of a teacher's time. It is also highlighted that in our daily conversations we do not use such words; therefore there is no need to teach them in class because children are not going to use them.

\section{Failure of the system to deliver professional development}

Some teachers are a threat to those who are willing to teach in mother tongue. One teacher said:

We want to do what others are doing, if we teach in isizulu parents and other teachers think we are not qualified or we do not know English. So to avoid that we do as others do and this satisfies the parents too.

Teachers who use isizulu are intimidated. When teachers join a school they speak correct African languages. Later they realise that other teachers do not teach the way they do, so they change to assimilate the popular behaviour.

\section{The perception of the failure of the education system}

Teachers highlighted that some problems are caused by the education system. Some teachers were redeployed to schools where another language dominates and is used as the Language of Learning and Teaching. One respondent stated:

I was redeployed to teach in this school. I don't know the language fully. I was made to teach Grade R learners with this shallow knowledge. I decided to use English for the benefit of learners.

Thus, some teachers do not find it comfortable to teach in another African language other than their own, therefore they prefer to use English. 


\section{Teachers' lack of proficiency in mother tongue}

Some teachers from urban areas who go to rural areas to teach are not proficient in African languages. One explained:

Teachers who are from urban areas do not speak proper languages and they do not know our dialects therefore they teach poor language. Its better if they teach in English.

Teachers prefer English to an African language that is not correct. Teachers themselves who know that they are not well grounded in the language find it difficult to teach in an African language and therefore teach in English.

\section{Translated resources}

All the foundation phase curriculum documents are in English and are difficult to translate. This encourages teachers to teach in English. Teachers state that even the story books and other resources, such as charts do not have proper African words. One respondent stated:

Charts have months of the year that are a direct translation for example 'January' is 'Januwari'.

These teachers are against the use of English words in the form of isizulu, or the 'zulufication' strategy. One respondent stated:

If the country is serious about teaching in mother tongue, they should inform the publishers to use proper words of the months like 'uMasingana'.

One teacher claimed:

We want to avoid inconsistency that is why we prefer teaching these in English.

Teachers state that they are encouraged by resources to teach in the way they do. Resources are directly translated from English. Publishers do not do enough research to find the correct English words.

\section{Lack of parental involvement}

When asked about parental involvement and the rights they exercise on behalf of the learner in terms of the choice of the language, and the school policy, a teacher stated that they do not have a problem with parents of children. One respondent mentioned:

Parents do not worry us, they do not attend meetings and they do not complain about our way of teaching. In actual fact they are happy about the way we teach.

Parents do not dictate to teachers which language they should use in class. Most of them do not attend school meetings, nor do they participate in the decision making of the school. They rely on their teachers' decisions and they trust their children's teachers. They actually get excited if they children come home saying some basic English words and commend teachers for the hard work they do. 


\section{'Invisible' school policies}

Some teachers stated that school policy is not communicated to them. One teacher said:

I do not know if we have a school policy. This is my fourth year in this school. Nobody told me about it.

There is the language school policy but it is not emphasised.

Some teachers stated that they do have school policies but they do not adhere to these because there is nobody who tracks what they do in their classrooms and school policy is not something they are reminded of.

\section{Discussion: inherent tensions in the implementation of policy}

Findings indicate that teachers do not adhere to what the policy stipulates because of the challenges they face when teaching in an African language. Factors such as prior learner knowledge, better opportunities for children, time constraints, inferiority complexes of teachers, failure of the system of education, teachers' lack of proficiency in mother tongue, direct translated resources, lack of parental involvement in decision making and invisible school language policy motivate them to teach otherwise. It was mentioned that when children enter school they come with knowledge of some concepts in English, which teachers build on. Prior learner knowledge is a good foundation, which teachers should build on. They can use emergent literacy that children come to school with, to build a sound knowledge of mother tongue. It actually makes the task of the teacher an easier one if children come to school with some knowledge of English because the teacher has the task to give the child an equivalent of an African language. This should not be used as an excuse to avoid mother tongue teaching in the early years but as stepping stones to teach it.

Teachers shy away from mother tongue teaching in favour of using English because they are convinced that they are creating better opportunities for children because English is seen as the language of power. Children can be fluent in English without being introduced to it before the stipulated time. As long as children have good teachers, who can teach mother tongue well and then slowly introduce them to English, learners can become proficient in English. To avoid this as an excuse in breaching the policy on mother tongue teaching, the study recommends that there should be a strengthening of the teaching of English by good English teachers. Enough resources should be made available so that when learners start learning English as a subject six months into Grade 1, they are in a position to attain it. When they reach Grade 4, a level where the FAL is used as the medium of instruction, children would have acquired sound English. Alexander (2009) states that learners will be fluent in English provided they are taught by good English teachers, who are well grounded in the language. Thus, there is no need to teach through the medium of English in the foundation phase. 
The study shows that teaching in mother tongue is time consuming. Learners do not finish on time. Learners in early grades should be exposed to a number of writing exercises before they are introduced to actual writing. If these exercises are done well, by the time they are given activities requiring writing, they are able to control their writing. Thus, they do not use excessive time trying to write.

Results also indicate that African teachers who are good in African languages somehow have a low professional self-concept. They do not teach through the medium of these languages because they adopt the style of other teachers, who breach the policy and who may appear more powerful or more successful. Some teachers become discouraged because other teachers scorn them, so they change their teaching style and language. Among staff members there are those who are not competent enough in African languages because of their background. This therefore has a huge influence on the way they teach and then they influence others. Such teachers should be encouraged to be assertive and do what is right and influence others. They should be informed that they are good resources which the country needs, hence this is the era where African languages need to be promoted. They need to be informed that the richness of the language should be passed on to younger generations with pride. They should not feel intimidated by the transgressors.

The education system needs to revise their policy of redeploying teachers. The language of learners and teachers should be taken into consideration. It is also recommended that subject and language advisors from district offices give continuous support to foundation phase teachers. More focus is given to the upper phases in terms of support for language teaching, ignoring the phase which forms the foundation for learning.

Teachers' lack of proficiency in mother tongue also has a negative effect, encouraging teachers to act contrary to the policy. Teachers should be encouraged to use acceptable terms when teaching young children so they can assimilate these. As it is difficult to undo wrong words in children, teachers should be careful about the way they use language and should check language items they are unsure of before they teach. Some resources used in the foundation phase are a direct translation of English resources. Publishers should be encouraged to do thorough research to find appropriate equivalent words, so that children are taught African languages correctly. In some schools there is a lack of parental involvement in decision making. This study revealed that some parents do not even know what the language policy says. This is ignorance on their side. Parents should not let teachers play a role on their behalf. School language policies in some schools are not regarded as a priority, they are invisible. Communication of and adherence to school language policies is necessary. This study showed that school language policies are not communicated to teachers, nor are these emphasised. Full attention has to be paid to this by school management teams. 


\section{Conclusion}

This study showed that factors regarded as inhibiting mother tongue teaching in the early years are used by teachers as opportunities to divert the policy and to morph it to a practice that they believe to be more feasible. It was also found that they encounter difficulties in teaching through the medium of an African language; therefore they look for excuses to avoid teaching in the language of the child. Because of their perceptions of negative effects they avoid the practice that is generally regarded as the ones that constitute good pedagogy. The study concludes by advising all foundation phase teachers and all the stake holders in education to work on the issues highlighted as factors inhibiting mother tongue teaching. This is not one person's responsibility. The onus rests on all of us to support the constitution of the country, which emphasises the promotion of African languages. The National Education Language Policy also emphasises the maintenance of the language of the child in the foundation phase by applying a bilingual additive approach, so honouring and implementing the mother tongue. This practice will produce learners who know their identity and who can easily switch to a language of power, provided that the foundation is laid through proper mother tongue teaching.

\section{References}

Alexander, N. (2002). English unassailable but unattainable. The dilemma of language policy in education in South Africa. PRAESA Occasional Paper No 3. Cape Town: PRAESA/ University of Cape Town.

Alexander, N. (2003). The African renaissance and the use of African languages in tertiary education. PRAESA Occasion paper No 3. Cape Town: PRAESA/University of Cape Town.

Alexander, N. (2009). Mother tongue bilingual teaching is the key. A paper presented at the colloquium on mother tongue teaching in the early years, held at the University of KwaZulu-Natal on 22 May 2009.

Baron, B. A. \& Richardson, D. R. (1994). Human aggression, 2nd ed. NY: Plenum.

Dada, F., Dipholo, T., Hoadley, H., Khembo, E., Muller, S. \& Volmink, J. (2009). Report of the task team for the review of the implementation of the National Curriculum Statement. Pretoria: Government Printers.

Department of Education. (1997). Language in Education Policy. Pretoria: DoE.

Department of Education. (1996). South African Schools Act. Pretoria: DoE.

Department of Education. (2008). Foundations for learning campaign: laying solid foundations. Government Gazette, 30880.

Ebrahim, H. B. (2009). Training South African foundation phase teachers for linguistic diversity. A paper presented at the colloquium on mother tongue teaching in the early years, held at the University of KwaZulu-Natal on 22 May 2009. 
Giorgi, A. (1978). Convergence and divergence of qualitative methods in psychology. In: A. Giorgi, C. T. Fisher \& E. C. Murray (eds.), Duquesne studies in phenomenological psychology, 2. Pittsburgh: PA Duquesne University Press.

Hay, J. (2009). Steps forward and new challenges: indigenous communities and mother tongue education in southern Africa. International Journal of Bilingual Education and Bilingualism, 12(94): 401-413.

Henning, E. (2004). Finding your way in qualitative research. South Africa: Van Schaik.

Hopkins, G. A. (2005). Faculty motivation: a view from the Ivory Tower. Academic Leader, 21(4): 4-5.

Kunene, A. F. (2009). Implementing the language in education policy: challenges at school level. A paper presented at the colloquium on mother tongue teaching in the early years held at the University of KwaZulu-Natal on 22 May 2009.

lyamu, E. O. S. \& Ogiegbaen S. E. A. (2007). Parents and teachers' perceptions of mother tongue medium of instruction policy in Nigerian primary schools. Language, Culture and Curriculum, 20(2): 97-108.

Mashiya, N. (2010) Mother tongue teaching at the University of KwaZulu-Natal: opportunities and threats. Alternation, 17(1): 93-108.

Maslow, A. H. (1955). New knowledge in human values. New York: Harper.

Rose, D. \& Meyer, A. (2000). A universal design for individual differences. Educational Leadership, 58(3): 39-43.

Rose, D. \& Meyer, A. (2002). Teaching every student in the digital age: universal design for learning. Alexandria, VA: ASCD.

Skutnabb-Kangas, T. (2009). The stakes: linguistic diversity, linguistic human rights and mother tongue based multilingual education- or linguistic genocide, crimes against humanity and an even faster destruction of biodiversity and our planet. Keynote presentation at Bamako International Forum on Multilingualism, Bamako, Mali 19-21 January 2009.

Tassava, B. \& Ruderman, S. (1999). Application of escape theory to binge eating and suicidality in college women. Journal of Social and Clinical Psychology, 18(4): 450-466. 